\title{
Temporal and spatial patterns in the recruitment of coral-reef fishes in Barbados
}

\author{
Henri Vallès ${ }^{1, *}$, Donald L. Kramer ${ }^{1}$, Wayne Hunte ${ }^{2}$ \\ ${ }^{1}$ Department of Biology, McGill University, 1205 Avenue Docteur Penfield, Montreal, Quebec H3A 1B1, Canada \\ ${ }^{2}$ Department of Biological and Chemical Sciences, University of the West Indies, Cave Hill Campus, \\ University Drive, Cave Hill, St. Michael, Barbados (West Indies)
}

\begin{abstract}
We monitored the recruitment of 8 fish taxa at $10 \mathrm{~d}$ intervals for $1 \mathrm{yr}$ on 5 fringing coral reefs along a $15 \mathrm{~km}$ stretch of the west coast of Barbados, using benthic standard monitoring units of recruitment of fishes (SMURFs). SMURFs are designed to sample taxa that settle onto coral rubble, including cryptic species, and to minimize post-settlement predation. We deployed SMURFs in reef habitat to separate meso-scale processes from the small-scale influences of benthic habitat. Recruitment of most taxa occurred year-round, but was highly variable, with on average more than $50 \%$ of recruits collected on only $14 \%$ of the sampling dates, indicating the importance of frequent sampling. Temporal patterns within taxa were concordant across reefs, indicating coast-wide synchronous settlement, but differed among taxa. Within reefs, 2 taxa settled more frequently on SMURFs surrounded by non-preferred substrate, 1 exhibited the opposite pattern, and the remaining 5 showed no substrate associations. Recruitment to individual SMURFs was seldom correlated among taxa. Among reefs, recruitment of 4 taxa was consistently lower on the central coast and higher at the north and south ends, consistent with a previously identified tidally induced flow regime that reduces onshore larval transport near the center of the west coast; the remaining taxa exhibited other spatial patterns, challenging the generality of the role of hydrodynamics. Overall, this study expands the taxonomic range of recruitment studies, shows spatially coherent (over kilometers) but temporally variable (over tens of days) recruitment and reveals substantial diversity in patterns among concurrently settling taxa.
\end{abstract}

KEY WORDS: Gobiidae $\cdot$ Scaridae $\cdot$ Serranidae $\cdot$ Pomacentridae $\cdot$ Labridae $\cdot$ Habitat $\cdot$ Settlement Standard Monitoring Units of Recruitment of Fishes $\cdot$ SMURF $\cdot$ Rubble $\cdot$ Caribbean

Resale or republication not permitted without written consent of the publisher

\section{INTRODUCTION}

Among reef fishes, settlement after the planktonic larval phase is highly variable in time and space (Doherty 1991, Booth \& Brosnan 1995). This variability may be the major determinant of local adult abundance (Victor 1986, Doherty \& Fowler 1994), although its importance relative to post-settlement processes likely varies in both time and space (Sano 1997, Shima 1999, Caselle 1999, Doherty 2002). Variability in settlement results from interactive processes operating at multiple scales. These processes include reproductive timing (Robertson et al. 1988), egg and larval survival
(Bailey \& Houde 1989), larval retention near the reefs (Cowen \& Castro 1994), larval onshore movement (Kingsford \& Choat 1986) and selection of settlement habitat (Tolimieri 1995).

Near the time of settlement, local benthic habitat features have the potential to influence the settlement of coral-reef fishes through habitat selection, independent of larger scale processes that affect larval abundance (Holbrook et al. 2000). Late-stage larvae of coral-reef fishes can swim against ambient currents (Fisher 2005), have well-developed sensory capabilities (Kingsford et al. 2002, Leis \& McCormick 2002) and can respond to a wide range of cues associated with the benthic habitat 
such as reef zones (Gutierrez 1998), conspecifics (Lecchini et al. 2005) and substrate types (Öhman et al. 1998). Because benthic habitat characteristics such as substrate composition are relatively stable over time and easy to measure, understanding how they influence the distribution of fishes during settlement is a feasible step toward predicting spatial settlement patterns at local and, potentially, larger scales (Tolimieri 1998a, Holbrook et al. 2000, Munday 2002). In turn, accounting for the effect of local benthic habitat can help identify larger-scale processes influencing spatial patterns of settlement by eliminating a potentially confounding factor (Danilowicz et al. 2001).

Assessing the importance of local benthic habitat and larger-scale processes on settlement requires data on spatio-temporal patterns at relevant scales (Sale 1998). For example, temporal resolution at a scale of one to several days is needed to minimize the potentially distorting effect of early post-settlement mortality (Booth 1991). Spatial resolution at a scale of meters to tens of meters is needed to investigate the effect of substrate type on microhabitat selection (e.g. Tolimieri 1995). Data from locations over kilometers to tens of kilometers are needed to recognize effects of largerscale processes, such as persistent oceanographic features (Hamilton et al. 2006). Studies covering at least $1 \mathrm{yr}$ are needed to examine variability in settlement over temporal scales that are relevant to the demography of many coral-reef fishes (Robertson \& Kaufmann 1998). Thus, ideal data should (1) exhibit fine-scale temporal and spatial resolution, (2) incorporate multiple sites over intermediate to large spatial scales, and (3) include medium to long-term trends. Additionally, because species often differ in temporal (Walsh 1987, Sponaugle \& Cowen 1997) and spatial (Gutierrez 1998, Schmitt \& Holbrook 1999) patterns of settlement, multiple species are needed to attain generality.

Monitoring fine-scale spatial and temporal patterns of settlement of multiple taxa at different sites and over long time periods presents serious logistical challenges that have limited the spatial, temporal and taxonomic scope of studies of settlement in coral-reef fishes. Estimates of settlement have traditionally been obtained through recruitment surveys, i.e. direct counts of young fishes that have survived an arbitrary time period on the reefs (Doherty 1991). These surveys are convenient for examining the role of local substrate composition in relation to large-scale features (e.g. Danilowicz et al. 2001). However, post-settlement processes, particularly predation by resident fishes, can quickly change patterns established at settlement (Steele \& Forrester 2002), which will result in an inaccurate picture of settlement unless surveys take place very frequently (Booth 1991). Frequent monitoring of multiple, widely separated sites, however, is difficult because recruitment surveys are time-demanding and require trained divers (Doherty 1991). Furthermore, detection of recently settled fishes may vary with substrate type (Ebeling \& Hixon 1991), and taxa that are small or cryptic or select microhabitats hidden from view following settlement will be underestimated (Ackerman \& Bellwood 2000). This has resulted in a disproportionate number of recruitment studies on families with relatively conspicuous settlers, mainly pomacentrids, labrids and gobiids (Booth \& Wellington 1998, Doherty 2002).

Recently, Vallès et al. (2006) developed and tested a standard monitoring unit of recruitment of fishes (SMURF) (Ammann 2004) that shows potential to resolve some of these problems in coral reefs. These units are deployed on the substrate and allow rapid underwater collection of recently settled fishes without the need for visual detection. Predator exclusion experiments indicate low rates of predation by larger fishes on recently settled individuals inside these units (Vallès et al. 2006). Thus, SMURFs can be used to investigate the effects of nearby substrate composition on settlement while controlling for early post-settlement predation and habitat quality. Low predation also increases the likelihood that the estimates of recruitment will mirror settlement rate (Vallès et al. 2006). Furthermore, SMURFs require less overall effort than reef recruitment surveys (Vallès et al. 2006). Two divers can sample multiple sets of replicate SMURFs over distances of tens of kilometers on the same day, facilitating a synoptic view of settlement and the implementation of long-term studies.

Here, we report the results of a 12 mo study of the temporal and spatial patterns of concurrent recruitment of multiple taxa along the west coast of Barbados. We monitored recruitment at $10 \mathrm{~d}$ intervals by sampling 8 replicate SMURFs, separated by meters in reef habitat, at 5 sites separated by kilometers. Specifically, we ask (1) how consistent are temporal patterns of recruitment across sites within and among taxa; (2) are there consistent spatial differences in recruitment within sites (i.e. among SMURF locations) and among sites; and (3) which features of benthic habitat are associated with variation in recruitment within and among sites?

\section{MATERIALS AND METHODS}

SMURFs, study sites and sampling design. We monitored recruitment to rubble SMURFs, which consist of a thick layer of finger coral Porites porites fragments inside a removable wire-mesh basket that fits into a cylindrical container $(60 \mathrm{~cm}$ diameter $\times 13 \mathrm{~cm}$ high). Beneath the basket of rubble is a removable fiberglass 
mosquito-net bag. Two divers collect recruits (i.e. fishes that have settled since the previous survey) by squirting anesthetic (1 part clove oil, 4 parts $70 \%$ isopropanol, 9 parts seawater) into the rubble, lifting and shaking the basket of rubble, then retrieving the bag into which nearly all recruits fall (Vallès et al. 2006). Specimens are sorted to the lowest possible taxonomic level and preserved in $90 \%$ ethanol. For each taxon, we used published information and observations of pigmentation and size to establish the maximum standard length (SL) for specimens to be considered as having settled between surveys.

We selected 5 study sites near locations used during previous settlement studies (Sponaugle \& Cowen 1996a,b, 1997). These sites were at least $2 \mathrm{~km}$ apart and encompassed a $15 \mathrm{~km}$ section of the west (leeward) coast of Barbados (Fig. 1). They were located on fringing reefs, in the zone described by Lewis (1960) as the 'reef front,' which lies seaward of the spur and groove zone. The habitat is mainly a dense, patchy mixture of live coral heads and sponges, interspersed with small patches of sand and rubble.

SMURFs were deployed about 4 mo before the start of the study. At each site, a diver laid a $100 \mathrm{~m}$ transect parallel to shore and 50 to $60 \mathrm{~m}$ from the spur and groove zone. He positioned 8 SMURFs at $9 \mathrm{~m}$ intervals on sand patches closest to the transect line. There were no significant differences among sites in depth of

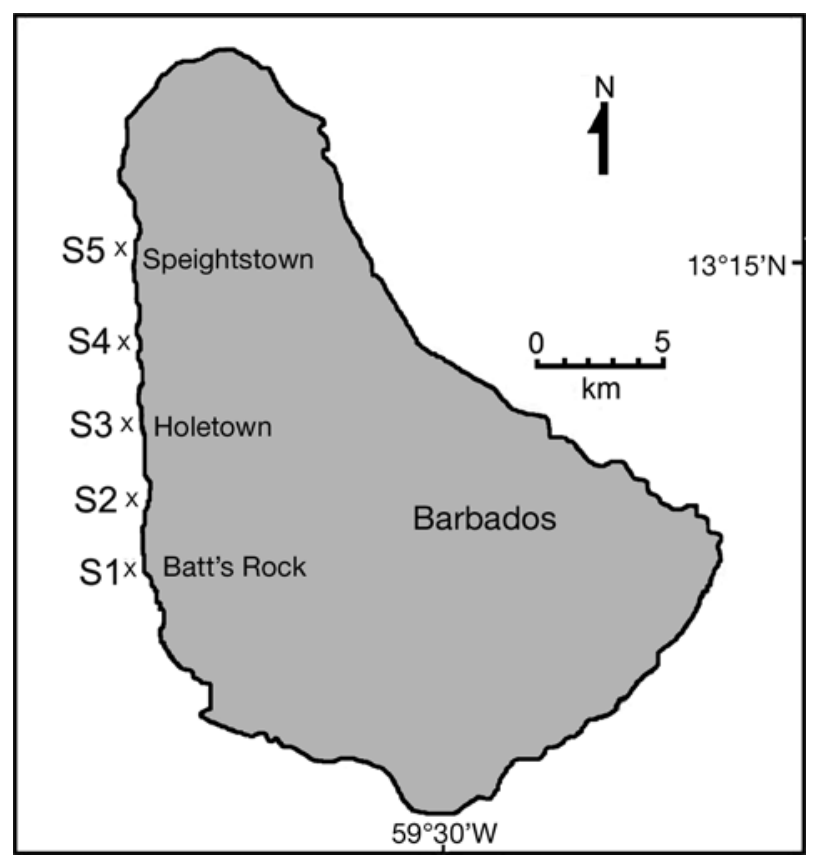

Fig. 1. Location of the 5 study sites along the west coast of Barbados. Site 1: $13^{\circ} 8^{\prime} 8^{\prime \prime} \mathrm{N}, 59^{\circ} 38^{\prime} 22^{\prime \prime} \mathrm{W}_{\text {; }}$ Site 2: $13^{\circ} 10^{\prime} 18^{\prime \prime} \mathrm{N}$, $59^{\circ} 38^{\prime} 27^{\prime \prime} \mathrm{W}_{\text {; }}$ Site 3: $13^{\circ} 11^{\prime} 48^{\prime \prime} \mathrm{N}$, $59^{\circ} 38^{\prime} 40^{\prime \prime} \mathrm{W}_{\text {; }}$ Site 4: $13^{\circ} 13^{\prime} 10^{\prime \prime} \mathrm{N}, 59^{\circ} 38^{\prime} 41^{\prime \prime} \mathrm{W}$; Site 5: $13^{\circ} 15^{\prime} 26^{\prime \prime} \mathrm{N}, 59^{\circ} 38^{\prime} 47^{\prime \prime} \mathrm{W}$
SMURFs $(8.7 \pm 0.1 \mathrm{~m}$, mean $\pm \mathrm{SE} ; \mathrm{n}=40 ;$ ANOVA: $F=$ 1.336; df $=4,35 ; \mathrm{p}=0.276)$. We collected recruits from 14 September 2003 to 19 September 2004, at approximately $10 \mathrm{~d}$ intervals $(10.3 \pm 0.1 \mathrm{~d}$, range 8 to $12 \mathrm{~d})$, depending on sea conditions, resulting in 36 consecutive sampling periods. During each period, we sampled all sites within $36 \mathrm{~h}$.

SMURFs were lost at some sites during 13 of the 36 sampling periods, resulting in 23 sampling periods with complete data. SMURF losses were caused by unusually rough sea conditions between 27 December 2003 and 9 April 2004 and the passage of Hurricane Ivan (6 September 2004). During 2 of these sampling periods, all SMURFs at all sampling locations were lost. During 3 other sampling periods, all SMURFs were lost from at least 1 site. These 5 sampling periods were excluded from some of our analyses, since there were no data on recruitment from at least 1 site. In late February 2004 at Site 1, we relocated 2 SMURFs that had been repeatedly affected by sea conditions. These relocated SMURFs were excluded from some of our analyses in which we compared recruitment among SMURFs within site.

Temporal consistency within and among taxa. We assessed synchrony in recruitment within taxa among sites by creating a temporal series for each taxon and site using the (square-root transformed) mean number of recruits caught per SMURF at each site per sampling period. We examined the similarity in the recruitment time series within taxa among sites and within sites among taxa using unweighted arithmetic average clustering (UPGMA) on a distance matrix containing Pearson correlation coefficients (i.e. distance $=1-\mathrm{r}$ ) between all recruitment series-pairs $(n=780)$. If recruitment occurred in synchrony across sites for each taxon, we expected the recruitment series to cluster by taxon. If recruitment occurred in synchrony across taxa for each site, we expected the recruitment series to cluster by site.

In addition, we assessed the overall degree of similarity among sites for each taxon by calculating the average Pearson correlation coefficient ( $\mathrm{r}$ bar) of all site-pairs as proposed by Thompson \& Page (1989). We estimated the significance of $r$ bar through restricted randomizations $(n=10000)$ based on random shifts of the recruitment series in relation to one another (i.e. caterpillar randomization) to account for autocorrelation present in some of the series (Fortin \& Dale 2005). We excluded the 5 periods during which all SMURF samples were lost from at least 1 site. We adjusted all $\mathrm{p}$-values according to the sequential Bonferroni correction procedure for multiple independent tests described by Hochberg (1988).

To test whether temporal patterns were correlated among taxa, we pooled data for each taxon across sites 
(the total number of recruits at all sites divided by the total number of SMURFs sampled). We then carried out Pearson correlation tests between all (square-root transformed) series pairs after removing a weak but significant linear trend from one of the series (Legendre \& Legendre 1998). The clustering and amongsite similarity analyses justified pooling the data (see 'Results'). We excluded the 2 periods during which all SMURF samples were lost at all sites. Degrees of freedom were corrected following Pyper \& Peterman (1998) to account for autocorrelation in some recruitment series. We adjusted p-values to account for multiple non-independent correlation tests using the sequential Bonferroni correction procedure described by Holm (1979). To facilitate visual comparison among taxa, we identified periods of high recruitment as those in which mean recruit abundance (pooled across sites) exceeded the 75th percentile of the entire pooled recruitment series for that taxon.

Spatial consistency within and among sites. For each taxon, we tested whether within-site recruitment was consistently higher in some SMURFs than others over time. We used a modified Friedman rank test that combined data from the 5 sites and used permutations to obtain a global test. First, we obtained a Friedman chi-squared statistic for each site, based on the observed ranks of SMURFs during each period; this measured the consistency in ranks over time. Then, we summed these statistics across sites to obtain a combined chi-squared statistic. Finally, we assessed the significance of the combined statistic by generating a null distribution based on 10000 permutations of SMURF ranks within sites and periods. To ensure identical sampling effort across SMURFs within sites, we used only data for the 23 periods with no SMURF losses and for those SMURFs that had never been relocated ( $\mathrm{n}=6$ SMURFs at Site $1, \mathrm{n}=8$ elsewhere). We used the Bonferroni correction to adjust $p$-values for multiple independent tests following Hochberg (1988).

To assess whether recruitment was consistently higher to some sites than others over time, we performed a Friedman rank test for each taxon (Zar 1999), where time period was the blocking factor and the site ranks were based on total number of recruits collected from the SMURFs in that period. To ensure identical sampling effort within sites, we used only data for the periods with no SMURF losses (23 periods); these periods represented $\geq 75 \%$ catch for all taxa, except for Gnatholepis thompsoni with 36\%. We then adjusted p-values following Hochberg (1988).

Associations between substrate composition and recruitment. To examine potential associations between recruitment onto SMURFs and the characteristics of nearby substrate, we first characterized the substrate using a point-contact method (Greig-Smith
1983). We laid five $5 \mathrm{~m}$ chain transects over the substrate radiating equidistantly from the outer perimeter of each SMURF, with one of the chains always pointing north. We then recorded substrate type at $20 \mathrm{~cm}$ intervals along each transect: 'live coral,' 'dead coral,' 'medium rubble' (5 to $20 \mathrm{~cm}$ diameter), 'small rubble' ( $<5 \mathrm{~cm}$ diameter) or 'sand'. We also measured rugosity (an estimate of physical complexity) at $1 \mathrm{~m}$ intervals using the ratio between the actual length of a given chain interval (i.e. $1 \mathrm{~m}$ ) and the straight horizontal distance between its 2 ends when it had been laid over the substrate (Luckhurst \& Luckhurst 1978).

To examine how substrate composition at increasing distance from the SMURFs affected recruitment, we created 3 data sets based on the average values of the 5 transects over distances of 0 to $1 \mathrm{~m}, 0$ to $2 \mathrm{~m}$ and 0 to $5 \mathrm{~m}$. These data sets were range-transformed across SMURFs (Legendre \& Legendre 1998). Then, for each distance interval, we quantified the variation in abundance of the 8 taxa that could be explained by the substrate variables and the sites. We used canonical redundancy analysis (RDA) with abundance of each taxon (rank-transformed sum of catches per SMURF) as the response variables, substrate variables as the explanatory variables and a set of dummy variables identifying the sites. We adjusted p-values within each set of RDAs following Holm (1979) to account for non-independent tests across distance intervals. The MANOVA and RDAs were performed using the software Canoco (Version 4.5 for Windows, Microcomputer Power) (ter Braak \& Smilauer 2002). Significance tests were carried out through permutations $(n=9999)$.

To separate the contributions of local substrate composition (within sites) and larger-scale processes (across sites) to variation in recruitment, we also carried out a variation partitioning separately for each taxon, following Borcard et al. (1992). Using a multiple regression approach with recruit abundance of each taxon (rank-transformed sum of catches per SMURF) as the response variable, we separated the variation in recruit abundance explained by (1) the substrate surrounding the SMURFs after removing the effect of sites, (2) the sites after removing the effect of substrate and (3) the co-variation between sites and substrate, i.e. shared variation. This approach also allowed us to test the statistical significance of the independent (non-shared) contributions of substrate and sites. The shared variation is obtained by removing the independent contributions of substrate and sites and is not directly amenable to tests of significance. To examine the effect of the substrate after removing that of sites, we used a subset of substrate variables previously identified through forward selection $(p<0.05)$ as explanatory variables and the dummy variables identifying sites as co-variables. If no substrate variables 
were selected through forward selection, we considered the variation accounted for by the substrate to be negligible and only estimated the variation accounted for by the sites. To examine the effect of the sites after removing that of substrate, we repeated the analysis using the sites as explanatory variables and the selected substrate variables as co-variables. These analyses were carried out using R 2.2.1 (http://cran.rproject.org/). Forward selection was performed using 9999 permutations with the 'packfor' package developed by S. Dray: forward selection with permutation (Canoco p. 46), Version 0.0-6. (http://biomserv.univlyon1.fr/ dray/). We performed the variation partitioning and assessed the significance of variation components using the 'varpart' function - 'vegan' package, Oksanen et al. (2005) - and 'ANOVA' function ('stats' package), respectively. We adjusted p-values of variation components within each combination of taxon and distance interval following Holm (1979). Variation explained is reported as adjusted $r^{2}$ to allow for the comparison of models within and across taxa (Legendre \& Legendre 1998).

We also assessed associations between pairs of taxa within sites by using Pearson correlations of the residuals of recruit abundance after removing the effect of sites. Significance tests were carried out through permutations ( $\mathrm{n}=9999$ ) using the 'corrperm' application developed by P. Legendre (www.bio.umontreal.ca/ legendre). Again, we adjusted p-values following Holm (1979) to account for multiple non-independent correlation tests.

In all above analyses, we used only data for the 23 periods with no SMURF losses and for those SMURFs that had never been relocated ( $\mathrm{n}=6 \mathrm{SMURF}$ s at Site 1, $\mathrm{n}=8$ elsewhere). There were no highly skewed variables in either the substrate or recruit data. Overall, there was no consistent evidence of spatial pattern within sites because recruit abundance and substrate composition were rarely significantly associated with the distance between SMURFs (only 4 out of $70 \mathrm{Mo-}$ ran's I tests yielded p-values < 0.05). We therefore treated SMURFs as independent replicates.

\section{RESULTS}

\section{General patterns}

In 1257 SMURF samples, we captured 3757 fish specimens $(2.99 \pm 0.09$ per sample), many still exhibiting pigmentation characteristic of the pelagic stage. In this study, we focus on the 8 most abundant taxa, one pomacentrid (Stegastes partitus), one serranid (Pseudogramma gregoryi), one labrid (Thalassoma bifasciatum), 2 scarids (Sparisoma spp. and Scarus spp.) and 3 gobiids (Lythrypnus nesiotes, Coryphopterus spp., Gnatholepis thompsoni), which together accounted for $91.7 \%(n=3445)$ of all the specimens caught (Table 1$)$. Based on local juvenile/adult abundance, Sparisoma spp. is most likely $S$. viride and/or $S$. aurofrenatum and Scarus spp. is most likely $S$. croicensis and/or $S$. taeniopterus $(\mathrm{H}$. Vallès unpubl. data). Based on DNA analyses, Coryphopterus spp. includes both C. dicrus and C. glaucofraenum (B. Victor pers. comm.).

All taxa recruited over most of the study period but showed high short-term temporal variability (Fig. 2). Seven of the 8 taxa were caught in at least 11 of the 12 mo and at least $68 \%$ of periods sampled (Fig. 2, Table 1). The exception was Thalassoma bifasciatum with catches in only 8 mo and $41 \%$ of periods (Fig. 2, Table 1). Most recruitment occurred in only a few pulses; on average, 4.75 periods (14\%) accounted for

Table 1. The 8 most abundant taxa listed in order of total number of specimens recorded (n) and showing size criteria (i.e. maximum standard length in $\mathrm{mm}$ ) used to consider specimens as newly settled, mean number of specimens per standard monitoring units of recruitment of fishes (SMURF) sample \pm standard error over the entire series ( $\mathrm{n}=34$ sampling periods; Mean \pm SE), percentage of sampling periods in which specimens were caught (\% Period), maximum:minimum ratio of temporal series after excluding periods of zero catch (Max:Min), minimal number of periods to account for $>50 \%$ of total catch (P50\%), and date of yearly maximum recruit catch (Year Max)

\begin{tabular}{|c|c|c|c|c|c|c|c|c|}
\hline Taxon & Family & $\mathrm{n}$ & $\begin{array}{l}\text { Size } \\
\text { criterion } \\
(\mathrm{mm})\end{array}$ & Mean \pm SE & $\begin{array}{c}\% \\
\text { Period }\end{array}$ & Max:Min & P50\% & Year Max \\
\hline Stegastes partitus & Pomacentridae & 1107 & 15 & $0.88 \pm 0.06$ & $100 \%$ & 157 & 4 & 19 May 2004 \\
\hline Sparisoma spp. & Scaridae & 997 & 10 & $0.79 \pm 0.04$ & $100 \%$ & 28 & 8 & 29 May 2004 \\
\hline Pseudogramma gregoryi & Serranidae & 541 & 12 & $0.43 \pm 0.03$ & $97 \%$ & 126 & 4 & 29 Apr 2004 \\
\hline Lythrypnus nesiotes & Gobiidae & 252 & 10 & $0.20 \pm 0.02$ & $91 \%$ & 42 & 6 & 18 Aug 2004 \\
\hline Coryphopterus spp. & Gobiidae & 203 & 10 & $0.16 \pm 0.01$ & $74 \%$ & 23 & 6 & 19 Apr 2004 \\
\hline Scarus spp. & Scaridae & 138 & 10 & $0.11 \pm 0.01$ & $74 \%$ & 19 & 5 & 18 Aug 2004 \\
\hline Thalassoma bifasciatum & Labridae & 108 & 12 & $0.09 \pm 0.01$ & $41 \%$ & 41 & 2 & 25 Nov 2003 \\
\hline Gnatholepis thompsoni & Gobiidae & 99 & 10 & $0.08 \pm 0.01$ & $68 \%$ & 40 & 3 & 28 Jan 2004 \\
\hline Total & & 3445 & & $2.74 \pm 0.09$ & & & & \\
\hline
\end{tabular}



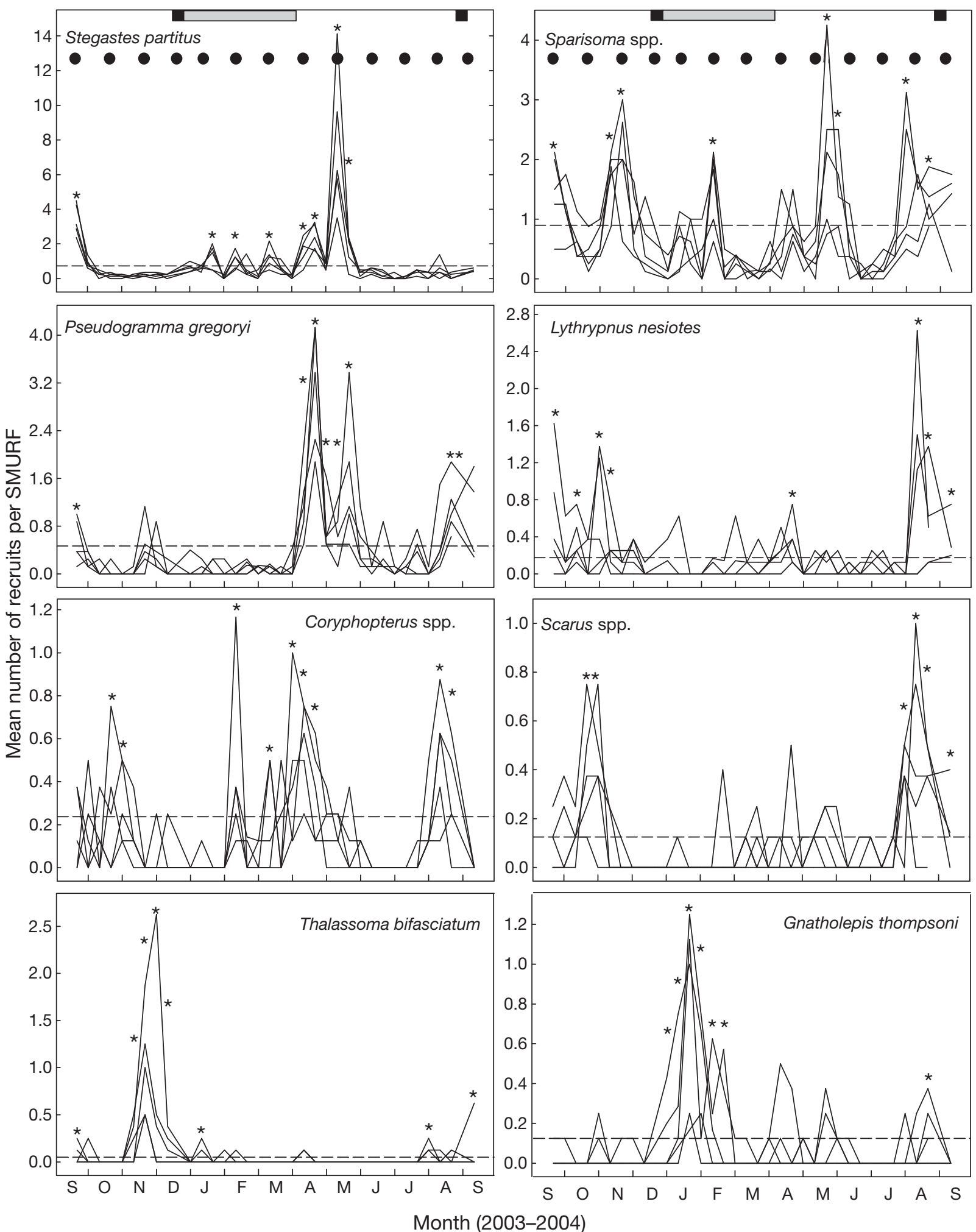

Fig. 2. Mean recruit abundance per SMURF over 36 consecutive 10 d sampling periods (September 14, 2003 to September 19, 2004 ) at 5 study sites along the west coast of Barbados. Panels are ordered from left to right and downward by decreasing overall numbers of specimens caught. ( ${ }^{*}$ Periods of high recruitment (pooled mean $>75$ th percentile, dashed horizontal line). Black circles represent the time of new moon. Top small black bars represent periods of completely missing data (shown as interpolated values from adjacent periods). Top horizontal grey bar represents a period of unusually rough sea conditions that resulted in SMURF losses at some sites. Note difference in ordinate scale among panels 
$50 \%$ or more of the recruits, although this value varied substantially among taxa (Table 1). After pooling the data across sites and excluding sampling periods with no captures, the ratio of the maximum:minimum catch per SMURF ranged from 19 to 157 across taxa (Table 1). To determine whether variability was affected by sample size, we examined the correlations between the measures of temporal variability (number of periods to reach $50 \%$ and maximum:minimum ratio) and the total number of specimens caught across taxa; these correlations were not significant (Spearman's $r_{s} \leq 10.494 \mid, N=8, p \geq 0.213$ ). The yearly maximum of the pooled series occurred on different dates for all taxa except Scarus spp. and Lythrypnus nesiotes (Table 1).

Temporal consistency within and among taxa. For each taxon, recruitment pulses often occurred synchronously at different sites, although the strength of this synchrony varied among taxa (Fig. 2). In contrast, the magnitude and timing of periods of high recruitment varied substantially across taxa (Fig. 2). The UPGMA cluster analysis indicated higher temporal consistency within than among taxa. With only 4 exceptions among the 40 series from 8 taxa and 5 sites, all 5 sites were allocated to a distinct cluster for each taxon (Fig. 3). The exceptions occurred at sites with relatively few specimens for the particular taxon. The cluster analysis also suggested that some pairs of taxa were more similar to each other in recruitment patterns than others. For example, the node joining most series of Lythrypnus nesiotes and Scarus spp. was at a low distance relative to the node joining these 2 taxa to most of the Gnatholepis thompsoni series (Fig. 3).

For each taxon, the similarity of the temporal patterns across sites was confirmed by the permutation tests of $\bar{r}$ (all adjusted $\mathrm{p} \leq 0.009$ ), with $\overline{\mathrm{r}}$ varying between 0.17 (G. thompsoni) and 0.83 (Stegastes partitus). There were no significant temporal correlations between the pooled series of the different taxa (all Pearson's $\mathrm{r}<10.55 \mathrm{l}$, all adjusted $\mathrm{p}>$ 0.286 , except between $L$. nesiotes and Scarus spp., Pearson's $\mathrm{r}=0.60$, adjusted $\mathrm{p}=0.059$ ).

Spatial consistency within and among sites. Within sites, taxa varied in patterns of preferential recruitment to particular SMURFs. Stegastes partitus showed highly significant within-site as-
Table 2. Consistency in the ranking of SMURFs within sites (Within-site) and in the ranking of 5 study sites (Among-site) over time for each taxon using a Friedman rank test approach. Within-site consistency was tested by producing a global Friedman chi-squared statistic combining data from all sites $\left(\Sigma \chi^{2}\right)$ and assessing its significance through within-site randomizations of SMURF ranks (see text). Among-site consistency was tested using a Friedman chi-squared statistic based on site ranks over time $\left(\chi^{2}\right)$ and assessing its significance with a chi-squared distribution with 4 degrees of freedom. Hochberg (1988) correction for multiple independent tests across taxa applied to generate $\mathrm{p}$-values

\begin{tabular}{|lrrrr|}
\hline \multirow{2}{*}{ Taxon } & \multicolumn{3}{c}{ Within-site } & \multicolumn{2}{c|}{ Among-site } \\
& $\Sigma \chi^{2}$ & $\mathrm{p}$ & \multicolumn{1}{c|}{$\chi^{2}$} & \multicolumn{1}{c|}{$\mathrm{p}$} \\
\hline Stegastes partitus & 78.7 & $<0.001$ & 13.3 & 0.023 \\
Sparisoma spp. & 50.4 & 0.108 & 29.7 & $<0.001$ \\
Pseudogramma gregoryi & 51.7 & 0.089 & 26.1 & $<0.001$ \\
Lythrypnus nesiotes & 43.4 & 0.280 & 20.3 & 0.003 \\
Coryphopterus spp. & 46.7 & 0.185 & 6.7 & 0.154 \\
Scarus spp. & 51.9 & 0.089 & 18.9 & 0.004 \\
Thalassoma bifasciatum & 27.8 & 0.930 & 15.0 & 0.019 \\
Gnatholepis thompsoni & 18.0 & 0.930 & 13.9 & 0.023 \\
& & & & \\
\hline
\end{tabular}

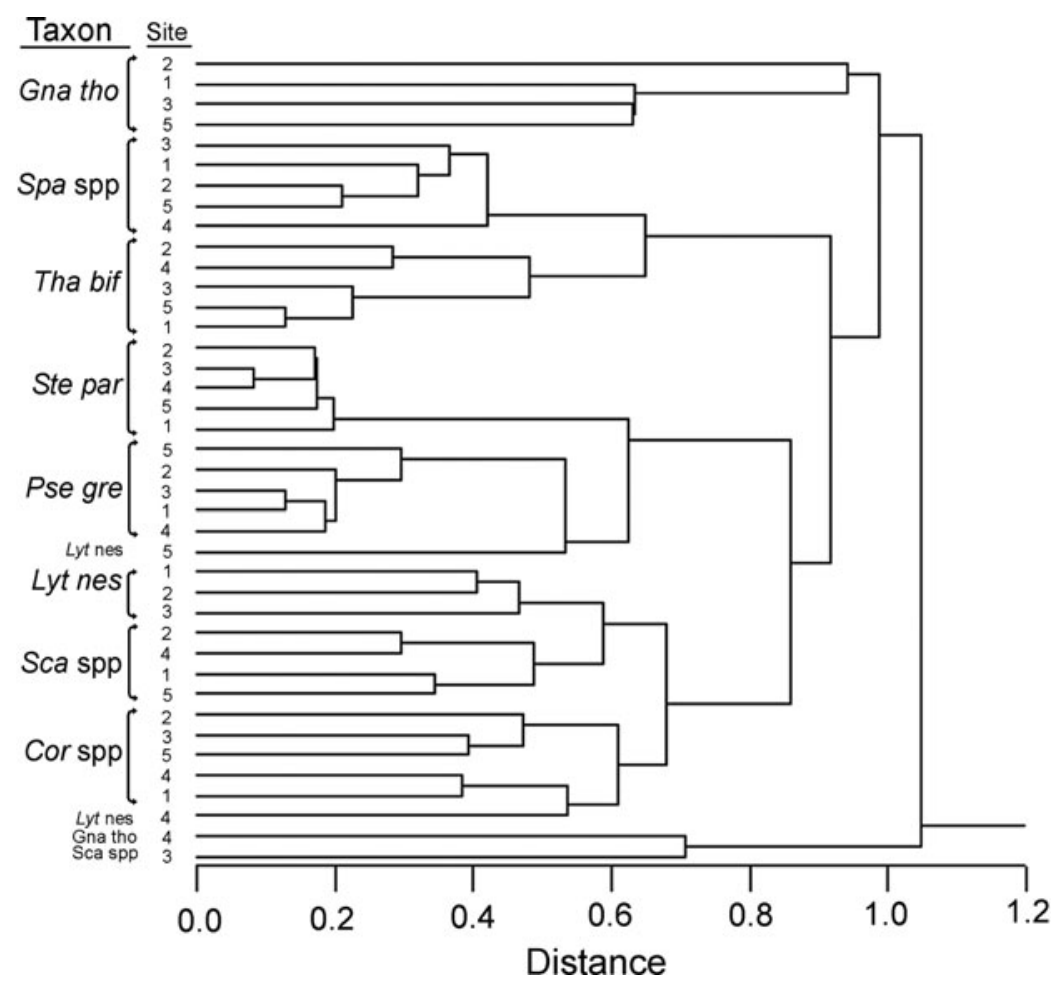

Fig. 3. Clustering of the temporal series (i.e. square-root of mean abundance per SMURF per period) of each taxon at each site using UPGMA clustering of a distance matrix based on Pearson correlation coefficients (i.e. distance $=1-\mathrm{r}$ ) among series pairs. Abbreviations of taxa are Gna tho (Gnatholepis thompsoni), Spa spp (Sparisoma spp.), Tha bif (Thalassoma bifasciatum), Ste par (Stegastes partitus), Pse gre (Pseudogramma gregoryi), Lyt nes (Lythrypnus nesiotes), Sca spp (Scarus spp.) and Cor spp (Coryphopterus spp.). Sites are numbered from south (1) to north (5) 
sociations (Table 2). We found no significant within-site associations for the remaining taxa, although for Pseudogramma gregoryi and Scarus spp., the associations were marginally non-significant ( $\mathrm{p}<0.1$, Table 2 ).

Across sites, all taxa except Coryphopterus spp. consistently recruited in higher numbers to some sites than to others (Table 2). Sparisoma spp., Pseudogramma gregoryi, Scarus spp. and Gnatholepis thompsoni, shared a pattern of low recruitment toward the central site (Site 3, Fig. 4). Stegastes partitus, Thalas-
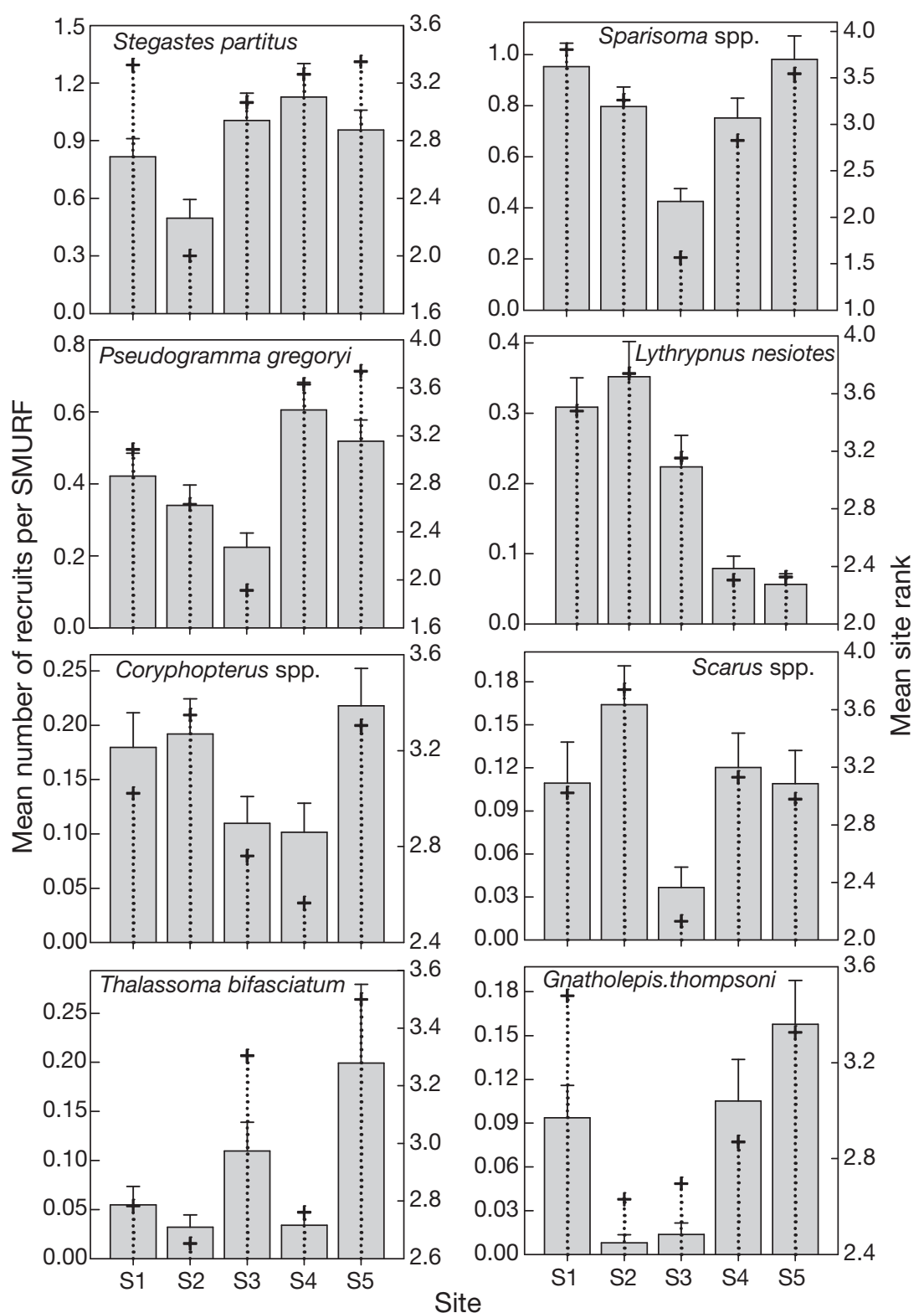

Fig. 4. Overall mean recruit abundance per SMURF sample + 1 SE (grey bars with solid line, $\mathrm{n}=1257$ SMURF samples) and mean site rank based on recruit abundance during 23 periods without SMURF loss (+ symbol with dotted line) for 8 taxa at 5 study sites along the west coast of Barbados. Sites are ordered from south (left) to north (right). Note difference in ordinate scale among panels soma bifasciatum and Lythrypnus nesiotes, however, did not conform to this pattern (Fig. 4). Stegastes partitus exhibited low catches only at Site 2, whereas T. bifasciatum exhibited low catches at Sites 1, 2 and 4. For L. nesiotes, catches decreased with increasing distance from Site 2 (Fig. 4).

Among sites for all taxa and periods combined, there was a pattern of lower recruitment toward the central site. Site 3 exhibited the lowest mean percentage of the total catch per taxon $(14.1 \% \pm 2.8)$, followed by the 2 adjacent central sites (Site $4: 17.8 \% \pm 2.8$ and Site $2: 18.5 \% \pm 4.1$ ), with highest values at the southern and northern sites (Site 1: $22.3 \% \pm 1.9$, Site 5: $27.4 \% \pm 4.7$ ).

Associations between substrate composition and recruitment. Sites differed in overall substrate composition (measured 0 to $5 \mathrm{~m}$ from SMURFs; MANOVA: $F=7.306, \mathrm{p}<0.001)$. The characteristics of the first, and, to some extent, the second meter differed from the 3 to $5 \mathrm{~m}$ intervals (Fig. 5). The first meter tended to have more sand, less live and dead coral, and lower rugosity, reflecting the placement of SMURFs on sand patches (Fig. 5). Despite such effects of distance, the RDAs explaining variation in recruitment yielded very similar results (within 1.3\%), whichever distance interval was considered. Hence, we only report the results of the overall 0 to $5 \mathrm{~m}$ distance. Most $(55.6 \%)$ of the variation in recruit abundance across all SMURFs could be explained by a model that included both the substrate variables and the sites $(F=3.378$, adjusted $\mathrm{p}<0.002$ ). Separate testing of the main axes revealed that only the first 2 were significant and both were highly correlated with the explanatory variables ( $r \geq 0.882$ ). Axis 1 accounted for $22.4 \%$ of the total variation in recruit abundance and for $40.3 \%$ of the variation that could be explained by the model $(F=7.805$, adjusted $\mathrm{p}<0.002)$. Axis 2 accounted for $15.6 \%$ of the total variation and for an additional $28.1 \%$ of the variation explained by the model $(F=6.787$, adjusted $\mathrm{p}<0.002)$.

The RDA biplot identified 3 groups of taxa based on substrate characteristics and sites (Fig. 6). The largest group, including Pseudogramma gregoryi, Sparisoma spp., Scarus spp., Coryphopterus spp. and, to a lesser extent, 


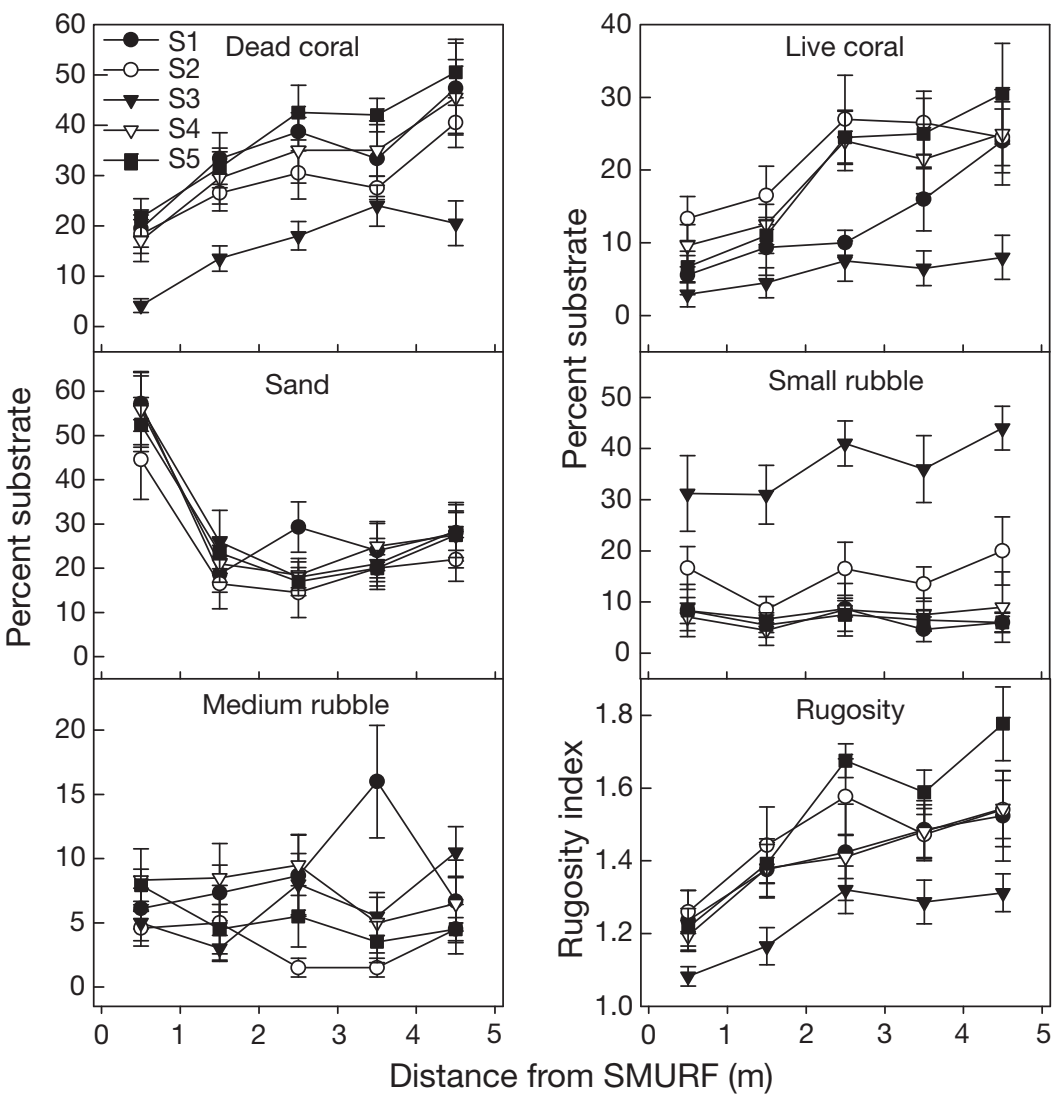

Fig. 5. Mean percentage \pm 1 SE (error bars) of the 6 substrate types characterizing the SMURF surroundings at increasing distance from the SMURFs at the 5 study sites ( $\mathrm{S} 1$ to $\mathrm{S} 5 ; \mathrm{n}=6$ at $\mathrm{S} 1$ and $\mathrm{n}=8$ elsewhere)
Gnatholepis thompsoni, was negatively associated with Site 3, the site with the least live and dead coral and lowest rugosity, but the most small rubble (Fig. 6). Stegastes partitus and Thalassoma bifasciatum were negatively associated with Site 2, the site with least sand, while Lythrypnus nesiotes was positively associated with this site (Fig. 6).

The independent and shared effects of the substrate composition and sites on recruitment differed among taxa as indicated by variation partitioning. Stegastes partitus, Coryphopterus spp. and Scarus spp. showed a significant effect of substrate on recruitment, independent of site location (Fig. 7). These 3 taxa differed in the substrate variables associated with recruitment and in the distance from the SMURFs at which substrate associations were significant. Stegastes partitus was positively associated with sand across all distances (adjusted p-values $\leq$ 0.017, Fig. 7). In contrast, Coryphopterus spp. exhibited a significant positive association with dead coral and a negative association with medium rubble (adjusted $\mathrm{p}=0.045$ ), but only at the 0 to $1 \mathrm{~m}$ distance (Fig. 7). Scarus spp. exhibited positive associations with rugosity and dead coral, but only at the 0 to $1 \mathrm{~m}$ and 0 to $2 \mathrm{~m}$ distances, respectively (adjusted p-values $\leq$ 0.049, Fig. 7). In the best explanatory models (i.e. those with highest total adjusted $\mathrm{r}^{2}$ ) for each taxon, substrate alone accounted for the largest portion of explained variation for Stegastes partitus (0 to $5 \mathrm{~m}$ ) and Coryphopterus spp. (0 to $1 \mathrm{~m}$ ), but the pattern was reversed for Scarus spp. (0 to 2 m, Fig. 7).

All taxa except Coryphopterus spp. showed a significant site effect, independent of the substrate composition. For Stegastes partitus, Pseudogramma gregoryi, Lythrypnus nesiotes and Gnatholepis thompsoni the site effect was significant across all distance intervals (adjusted p-values $\leq 0.018$ ). For Sparisoma spp. and Scarus spp., the site effect was significant only at the 2 smallest distances (adjusted $\mathrm{p}$-values $\leq 0.049$ ), whereas for Thalassoma bifasciatum the site effect was significant only at the largest distance (adjusted $\mathrm{p}=0.049$ ). Except for Coryphopterus spp., site alone consistently accounted for approximately onethird or more of the explained variation in the best explanatory models of each taxon (Fig. 7).

The proportion of explained variation in recruitment associated with the co-variation between the substrate composition and sites (i.e. shared variation) was considerable for 5 taxa. It accounted for approximately one-third or more of the explained variation in the best explanatory models of Sparisoma spp., Pseudogramma gregoryi, Scarus spp., Gnatholepis thompsoni and Thalassoma bifasciatum (Fig. 7). In contrast, this shared variation played a comparatively negligible role in explaining the recruitment of Stegastes partitus, Coryphopterus spp. and Lythrypnus nesiotes (Fig. 7).

We found only one significant association in SMURF use within sites for pairs of taxa, i.e. a positive association between Coryphopterus spp. and Gnatholepis thompsoni $(\mathrm{r}=0.5, \mathrm{n}=38$, adjusted $\mathrm{p}=0.042$; in all other cases: $r<10.292$, adjusted $p$-values $>0.9$ ).

\section{DISCUSSION}

\section{Overall temporal patterns}

Studies documenting coral-reef fish recruitment with at least biweekly sampling over a full annual cycle have generally revealed high temporal variability, 


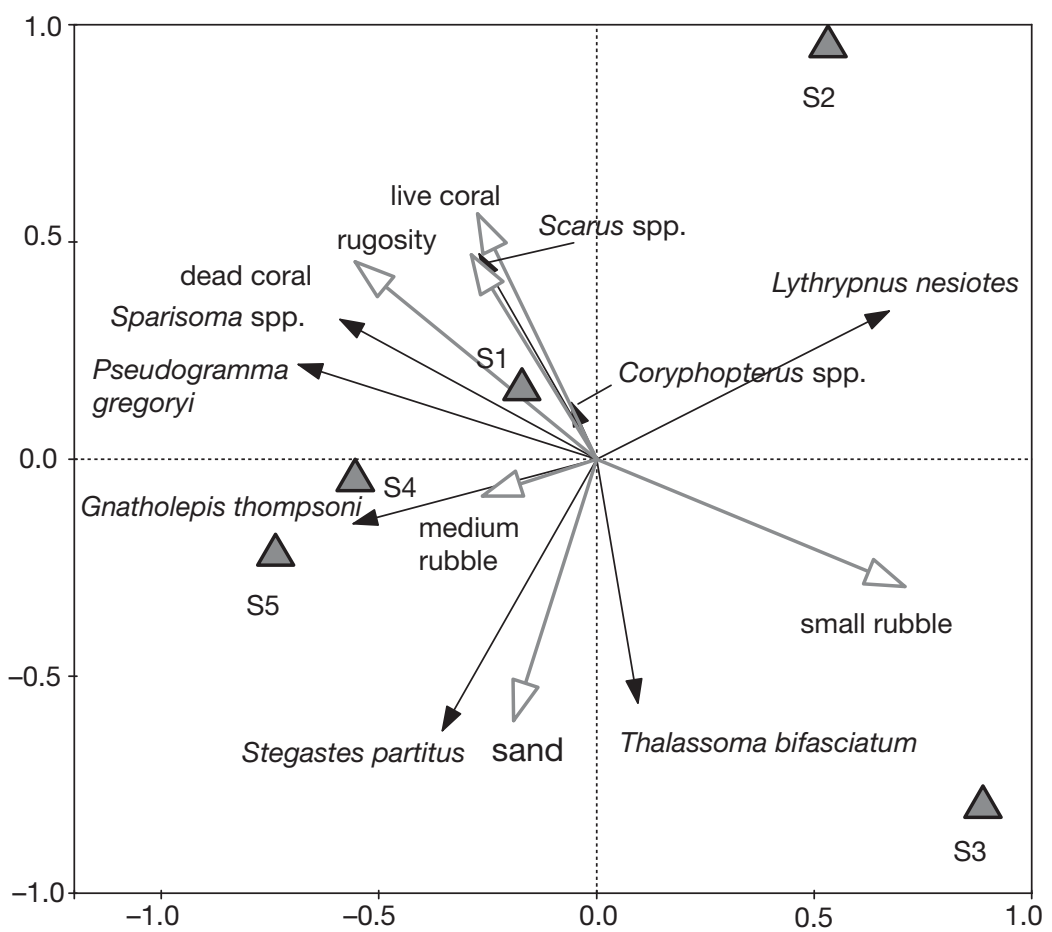

Fig. 6. Biplot of the redundancy analysis (RDA) using cumulative recruit abundance of 8 taxa on SMURFs as response variables and site location and the substrate variables as explanatory variables. Substrate data of the first $5 \mathrm{~m}$

( 0 to $5 \mathrm{~m}$ interval) were used

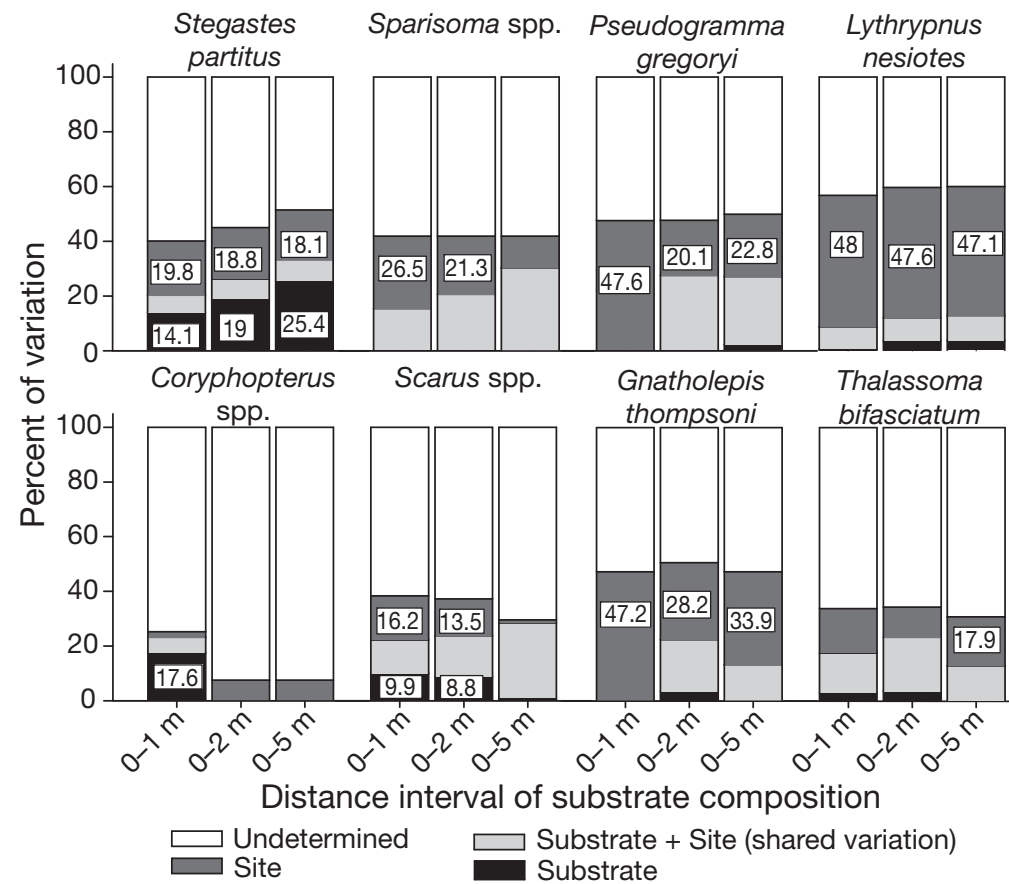

Fig. 7. Partitioning of variation performed for each taxon considering substrate composition around SMURFs at different distance intervals (i.e. $0-1 \mathrm{~m}, 0-2 \mathrm{~m}, 0-5 \mathrm{~m}$ ). This analysis separates contributions of substrate composition, sites and shared effect (Substrate + Site) to explain variation (as adjusted $r^{2}$ ) of recruit abundance across SMURFs. Numbers on bars indicate those independent (non-shared) variation components (i.e. substrate and/or site) that were significant after corrections for multiple non-independent tests within each taxon-distance interval combination spanning 1 to 2 orders of magnitude (e.g. Luckhurst \& Luckhurst 1977, Tupper \& Hunte 1994, Booth \& Beretta 1994, Sponaugle \& Pinkard 2004, but see McFarland et al. 1985 for variability reaching 3 orders of magnitude). In our study, recruitment showed high temporal variability for all taxa, with differences among sampling periods also reaching 1 to 2 orders of magnitude. The reduced predation in SMURFs (Vallès et al. 2006) might have been expected to decrease density-dependent mortality (Hixon \& Webster 2002) and therefore increase variability, but this did not seem to be the case. On the other hand, the potential inclusion of more than 1 species in Scarus spp., Sparisoma spp. and Coryphopterus spp. might have decreased our variability estimates, as a result of weak correlations in timing among species. Although some variability could have been an artifact of low catches, the lack of correlation between variability estimates and overall catch across taxa suggests that this was not a major factor. For several taxa that are cryptic (Scarus spp. and Sparisoma spp.) or remain hidden under the substrate ( $\mathrm{Ly}$ thrypnus nesiotes and Pseudogramma gregoryi) immediately after settlement, our study provides the first year-long evidence that individuals less than $10 \mathrm{~d}$ post-settlement show levels of variability similar to more conspicuous taxa.

Recruitment occurred year-round for most taxa, supporting the idea that recruitment in the tropical Western Atlantic exhibits less marked seasonal patterns than in the Great Barrier Reef (Robertson \& Kaufmann 1998). Thalassoma bifasciatum was, however, virtually absent from catches between March and July, which contradicts previous studies in Barbados reporting year-round recruitment of this species, albeit with variable intensity (Hunt von Herbing \& Hunte 1991, Tupper \& Hunte 1994, Sponaugle \& Pinkard 2004). The dominant recruitment pulse observed in November did coincide with the most notable abundance of $T$. bifasciatum recruits on adjacent natural reefs during the entire series ( $H$. Vallès pers. 
obs.). However, the SMURFs may have missed smaller recruitment episodes because of rapid emigration following metamorphosis which, in other wrasses, occurrs after $5 \mathrm{~d}$ or less hidden in the substrate (Victor 1983).

\section{Temporal consistency within and among taxa}

Studies showing spatial coherence in recruitment at scales of one to tens of $\mathrm{km}$ have used 2 approaches to circumvent the difficulties of frequent visual counts at widely separated sites (Doherty 1991). One approach is back-calculation of settlement dates using otoliths of specimens collected at different times and sites (e.g. Victor 1984, Pitcher 1988). The other is measuring pelagic larval delivery in the plankton using lighttraps or nets deployed concurrently at multiple sites (e.g. Milicich \& Doherty 1994, Thorrold et al. 1994). In Barbados, Sponaugle \& Cowen (1996b, 1997) used otolith back-calculation of wrasses and larval supply of multiple taxa between March and June of 3 consecutive years to provide convincing evidence of coastwide synchrony in recruitment. In our study, recruitment occurred synchronously over at least $15 \mathrm{~km}$ of coastline for each taxon. Thus, we extend previous findings in Barbados by demonstrating that synchrony in recruitment is not restricted to a short period of the year, but persists year-round. Furthermore, we provide evidence of coast-wide synchrony for taxa that would normally go undetected in surveys of small recruits, while avoiding the limitations of otolith analysis based on older, conspicuous specimens (see Doherty 1991).

Several processes could account for coast-wide synchrony in recruitment, including the passage of fronts carrying larvae over the reefs and larval responses to large-scale settlement cues (Masterson et al. 1997). In Barbados, one such process likely involves both pelagic larval behavior and the existence of an onshore flow favoring larval retention near the west coast (Cowen \& Castro 1994). Recently, Paris \& Cowen (2004) showed that the ontogenetic vertical migration of Stegastes partitus larvae leads to the formation of larval patches up to $6 \mathrm{~km}$ long at depths corresponding to onshore flow, favoring near-shore retention along the west coast of Barbados. The occasional formation, retention and movement along the coast of such large patches, coupled with subsequent active movement of larvae to the reefs at the time of settlement (Leis 2006), could explain the coast-wide synchrony that we observed in $S$. partitus; similar processes may occur in the other taxa.

Temporal patterns of recruitment differed among taxa, indicating that whatever the combination of processes ultimately resulting in coast-wide synchrony, they appeared to act independently across taxa. Sub- sequent analyses (Vallès 2008) showed diversity among these taxa in the relationships between recruitment and several environmental variables, suggesting that the different temporal patterns are not purely the result of stochastic processes but may be partly driven by the environment. Together, these findings suggest distinct taxon-specific dynamics in the plankton, although we cannot exclude a role of reproductive timing in influencing recruitment patterns of some taxa (Hunt von Herbing \& Hunte 1991). Our study agrees with others documenting recruitment of multiple species over 1 yr or more in the Caribbean, which have also observed substantial inter-specific diversity in temporal patterns (e.g. Luckhurst \& Luckhurst 1977 in Curacao, Robertson 1990 in Panama, Booth \& Beretta 1994 in St. Thomas, Tupper \& Hunte 1994 in Barbados, Miller et al. 2001 in St. John).

\section{Spatial consistency within and among sites}

Small-scale (within-site) patterns

Small-scale patterns of recruitment could result from responses of settlers to small-scale flow patterns (Breitburg et al. 1995), resident fishes (Lecchini et al. 2005) and substrate characteristics (Tolimieri 1995, Öhman et al. 1998). Our study assessed preferential SMURF use by the settlers and then focused on potential effects of substrate. Stegastes partitus showed preferential SMURF use as well as a positive association with sand substrate around the SMURFs. Small juvenile $S$. partitus generally inhabit substrates with some 3-dimensional physical complexity (e.g. rubble mounds: Büttner 1996). One possible explanation for the pattern observed is that S. partitus, like some crustaceans (Stevens \& Kittaka 1998), avoids sand at settlement, making the SMURFs more attractive. Another explanation is that $S$. partitus prefers discrete patches of physically complex habitat surrounded by flat substrate to maximize the visual field, as recently proposed by Rilov et al. (2007).

Scarus spp. and Coryphopterus spp. did not show preferential SMURF use but did show associations with substrate characteristics. Substrate associations would be expected to be reflected in preferences among SMURFs. However, the rank tests used to assess consistent SMURF use over time often involved low counts, reducing the power relative to the analyses of substrate associations, which involved pooling all the data for each SMURF. Coryphopterus spp., like Stegastes partitus, preferentially used SMURFs surrounded by what appears to be less-preferred substrate. This taxon recruited predominantly onto SMURFs surrounded by more coral and less medium rubble, yet both Coryphopterus glaucofraenum and 
Coryphopterus dicrus are often found together inhabiting areas richer in sand and rubble ( $\mathrm{H}$. Vallès unpubl. data). In contrast, the abundance of Scarus spp. was positively associated with dead coral and rugosity, a pattern which is broadly consistent with the distribution of small recruits of this taxon (H. Vallès unpubl. data). In this case, SMURFs may have been perceived as the most suitable habitat while the surrounding habitat may have attracted settlers to an area or facilitated their movement toward the SMURFs.

Five taxa showed no significant evidence of preferential SMURF use and no associations with substrate variables. This suggests that neither the measured variables nor other unmeasured substrate characteristics that differed among SMURFs influenced settlement location, resulting in random settlement onto SMURFs. However, the limited power of the analysis of SMURF preference means that this conclusion must be tentative, as suggested by the marginally non-significant p-value for Pseudogramma gregoryi. The number of recruits could affect the probability of finding an effect of substrate. For example, Coryphopterus spp. showed an association with substrate characteristics, but Gnatholepis thompsoni did not, even though abundance of the 2 species among SMURFs was correlated, perhaps because there were 4 times as many Coryphopterus spp. recruits. Apparently random settlement is consistent with the lack of within-site correlations among most taxa and could occur if taxa are attracted to several kinds of structurally complex substrate, as are some crustaceans (Moksnes \& Heck 2006), or if all locations tested are equally suitable. For example, Tolimieri (1998b) found that Sparisoma viride exhibited no settlement preferences between small patch reefs of different composition and physical complexity.

The idea that habitat selection of coral-reef fishes operates at multiple spatial scales (Kingsford et al. 2002) implies that settlement and specific features of the surrounding habitat may be significantly associated only over certain distances. Furthermore, differences among taxa in perceptual (Job \& Bellwood 2000) and locomotor (Fisher et al. 2005) capabilities may result in differences in the spatial scale at which different taxa are capable of detecting or responding to microhabitat cues. This may explain why Stegastes partitus responded consistently to the substrate averaged over all distances from the SMURFs, whereas Coryphopterus spp. and Scarus spp. only did so at the smallest distances. Stegastes partitus larvae are larger and thus probably better swimmers than Coryphopterus spp. and Scarus spp. (Stobutzki \& Bellwood 1997, Fisher et al. 2005), and therefore may be capable of exploring a wider area. Although the exact role of substrate characteristics and scale during microhabitat selection can only be assessed through experiments, this analysis shows that simple measurements of the surrounding habitat can help account for some of the influence of small-scale spatial heterogeneity on recruitment onto SMURFs. Accounting for such influences was necessary to use the SMURFs for spatial comparisons at larger scales.

\section{Meso-scale (among-site) patterns}

Consistent differences in recruitment among sites at spatial scales similar to those examined in this study are common in coral-reef fishes (Fowler et al. 1992, Tolimieri et al. 1998, Booth et al. 2000, Hamilton et al. 2006). Predictable physical oceanographic processes may determine the location of such sites by transporting or retaining larger numbers of larvae in their vicinity (Hamilton et al. 2006). Alternatively, differences may be generated by habitat selection associated with differences in broad habitat characteristics (Doherty et al. 1996). In our study, sites differed in substrate composition, some sites received consistently more recruits than others for 7 of 8 taxa, and the relative importance of sites and substrate composition in explaining recruitment patterns differed among taxa. The importance of site location independent of substrate characteristics for all taxa except Coryphopterus spp., as revealed by variation partitioning, suggests an important role of hydrodynamics in setting meso-scale patterns. In Barbados, Sponaugle \& Cowen (1996b) noted that the nightly tidal flow was offshore and larval delivery low near our central Site 3, while flow was onshore with higher larval delivery at the northern and southern ends of the west coast near our Sites 1 and 5. This pattern of larval delivery is consistent with the observation of low recruitment towards the center, particularly at Site 3, in Scarus spp., Sparisoma spp., Pseudogramma gregoryi and Gnatholepis thompsoni. For Lythrypnus nesiotes, the gradual decrease in abundance away from Site 2 suggests alternative larval transport and/or retention mechanisms. Some gobies appear to spend their entire larval stage directly on the reef, exhibiting behavior that minimizes advection away from the reef (Potts \& McGuigan 1986). If $L$. nesiotes exhibited similar characteristics, then coast-wide hydrodynamics would likely have little effect on this species and its abundance could reflect local processes unrelated to benthic habitat (e.g. spawning). Unlike the other taxa, most recruitment of Thalassoma bifasciatum occurred in 1 single short episode and so the spatial pattern identified for this species warrants caution.

For Stegastes partitus and Coryphopterus spp., our findings suggest a more important role for microhabitat characteristics than for hydrodynamics as determinants of recruitment within and among sites. For both 
taxa, the variation partitioning revealed that substrate composition was more important than site location, even though $S$. partitus (but not Coryphopterus spp.) also exhibited a site effect. Given the previous evidence of habitat selection for $S$. partitus and the discreteness of the spatial pattern (i.e. low recruitment only at Site 2), this site effect likely reflects unmeasured benthic features rather than hydrodynamics further influencing habitat selection. For S. partitus, our results contrast with Sponaugle \& Cowen (1996a), who found no associations between $S$. partitus recruitment and habitat characteristics along the west coast of Barbados. If settlement substrates maximizing the visual field are important during habitat selection of $S$. partitus, as suggested above, then variability in suitable habitat would have been missed in Sponaugle \& Cowen's (1996a) benthic surveys, which focused only on substrate composition. For Coryphopterus spp., the lack of site effects during the among-site rank comparison and variation partitioning should be treated with caution, as it might reflect recruitment differences between Coryphopterus dicrus and Coryphopterus glaucofraenum at this scale.

Several meso-scale processes associated with differences in benthic habitat among sites may also have contributed to spatial patterns of some taxa. In particular, recruitment of Scarus spp., Sparisoma spp., Pseudogramma gregoryi and Gnatholepis thompsoni was low at Site 3, the site with highest small rubble and lowest coral. This resulted in considerable amounts of spatial variation in recruitment that could not be attributed unequivocally to benthic habitat or site location (i.e. shared variation) for these taxa, which could reflect 3 different meso-scale processes. First, it could reflect a higher depletion of larvae before they reach the SMURFs at Site 3, due to the more abundant alternative small rubble substrate potentially suitable for settlement, resulting in lower overall settlement onto SMURFs. In this case, the SMURFs would consistently under-estimate recruitment to the reefs at this site, which is a potential limitation of standard units of habitat when sites differ in substrate composition (Paula et al. 2006). Second, the shared variation could reflect meso-scale habitat selection (Doherty et al. 1996), whereby larvae prefer sites with higher coral cover or avoid sites with higher small rubble. Third, more small rubble and lower recruitment at Site 3 may be independent results of hydrodynamic processes. Site 3 generally suffered more coral damage and greater SMURF loss during periods of rough seas than the other sites (H. Vallès pers. obs.). Natural reef surveys coupled with experimental manipulations of habitat (e.g. Shima 2001) are required to distinguish the roles of larval depletion, site selection and larval delivery in recruitment patterns.

\section{CONCLUSION}

Recruitment was variable over time and generally year-round, implying that long-term, uninterrupted monitoring is necessary to identify environmental correlates of recruitment (Robertson \& Kaufmann 1998). The coast-wide synchrony in recruitment indicates that monitoring 1 site may suffice to provide a coastwide view of temporal patterns of recruitment in Barbados, thus reducing logistic effort associated with long-term monitoring. At the temporal scales of our study, recruitment variability will have a greater influence on the local population replenishment of shortlived taxa (e.g. gobiids) than of longer-lived species (e.g. scarids) (Warner \& Hughes 1988, Robertson \& Kaufmann 1998). Nevertheless, the importance of scarids for reef health (Mumby et al. 2006) and for small-scale fisheries (Dalzell 1996), as well as the paucity of data on the dynamics of the very early postsettlement stage of this family, means that all sources of variation in population size need to be considered. Studies using benthic SMURFs to capture the cryptic newly settled individuals therefore have potential for a unique contribution.

Although some sites received higher numbers of settlers than others for most taxa, ultimate effects on local population abundance will depend on the degree to which post-settlement processes modify patterns established at settlement (Jones 1991). Sites with higher recruitment are likely to exhibit stronger densitydependent mortality of recently settled fishes, particularly due to predation by resident fishes (Hixon \& Webster 2002). Density-dependent mortality can be strongly associated with abundance of suitable refuge habitat over several spatial scales (Forrester \& Steele 2004). Thus, habitat selection could play an important role in ensuring juvenile persistence (Wellington 1992) if it leads settlers to suitable refuge microhabitat. Although many coral-reef fishes exhibit specific microhabitat preferences at settlement (Öhman et al. 1998), the lack of consistent patterns of SMURF use for most of the taxa examined here suggests that some may have flexible microhabitat preferences. Thus, suitable refuge microhabitat at settlement may have been nonlimiting, and therefore strong effects of density-dependent post-settlement mortality may only operate on later juvenile stages (Steele 1997). Among the exceptions, Stegastes partitus was notable for both the apparent complexity of suitable settlement microhabitat and the uniqueness of its meso-scale pattern. For this species, habitat selection may also be the primary determinant of among-site recruitment patterns. In contrast, for several of the remaining taxa, coast-wide hydrodynamics appeared to play a more important role in setting among-site patterns. Such differences 
among taxa may partly reflect differences in the spatial scales at which they can respond to benthic habitat cues, underscoring the taxon-specific nature of the interaction between local benthic habitat and larger scale processes.

Although no single spatial (hydrodynamic and habitat selection) model explained the meso-scale patterns for all taxa, our site comparisons revealed that patterns were more similar for some taxa than for others, suggesting that recruitment of some (but not all) taxa is partially driven by the same physical processes and/or meso-scale settlement cues. Finally, we note that our study covered only a single year of recruitment, highlighting the need for further similar studies.

Acknowledgements. We thank A. Desrochers, M. Richardson, A.-C. Breault, A. Griffin, F. Hinds, L. Robertson, K. Baldwin, R. Goodridge, R. Roach, D. Roche, C. Bissada, D. Perez and the many other volunteer divers who provided assistance on the field. We particularly thank B. and M. Selliah and J. Horrocks for generous room and/or board support. We thank R. Haynes, B. Downey and the staff of Bellairs Research Institute of McGill University for logistical support. We are particularly indebted to B. Victor for specimen identification and to R. Mahon and H. Oxenford of the University of West Indies (UWI) for allowing us to use UWI-CERMES facilities and boat when needed. We thank P. Legendre and B. Leung for statistical advice. P. Legendre, S. Hamilton, and 3 anonymous reviewers provided comments that greatly improved the manuscript. This research was partially funded by UWI grants to W.H. and a Natural Sciences and Engineering Research Council of Canada Discovery grant to D.L.K. Additional support came from a PADI-AWARE project grant, and a Small Scheme grant from the Fisheries Society of the British Isles to H.V. Waddell Aquatics Dive Shop, Montreal, provided a substantial discount on diving equipment.

\section{LITERATURE CITED}

Ackerman JL, Bellwood DR (2000) Reef fish assemblages: a re-evaluation using enclosed rotenone stations. Mar Ecol Prog Ser 206:227-237

Ammann AJ (2004) SMURFs: standard monitoring units for the recruitment of temperate reef fishes. J Exp Mar Biol Ecol 299:135-154

Bailey KM, Houde ED (1989) Predation on eggs and larvae of marine fishes and the recruitment problem. Adv Mar Biol 25:1-83

Booth DJ (1991) The effects of sampling frequency on estimates of recruitment of the domino damselfish Dascyllus albisella Gill. J Exp Mar Biol Ecol 145:149-159

Booth DJ, Beretta GA (1994) Seasonal recruitment, habitat associations and survival of pomacentrid reef fish in the US Virgin Islands. Coral Reefs 13:81-89

Booth JB, Brosnan DM (1995) The role of recruitment dynamics in rocky shore and coral reef fish communities. Adv Ecol Res 26:309-385

Booth DJ, Wellington G (1998) Settlement preferences in coral-reef fishes: effects on patterns of adult and juvenile distributions, individual fitness and population structure. Aust J Ecol 23:274-279

Booth DJ, Kingsford MJ, Doherty PJ, Beretta GA (2000) Recruitment of damselfishes in One Tree Island lagoon: persistent interannual spatial patterns. Mar Ecol Prog Ser 202:219-230
Borcard D, Legendre P, Drapeau P (1992) Partialling out the spatial component of ecological variation. Ecology 73 : 1045-1055

Breitburg DL, Palmer MA, Loher T (1995) Larval distributions and the spatial patterns of settlement of an oyster reef fish - responses to flow and structure. Mar Ecol Prog Ser $125: 45-60$

Büttner H (1996) Rubble mounds of sand tilefish Malacanthus plumieri (Bloch, 1787) and associated fishes in Colombia. Bull Mar Sci 58:248-260

Caselle JE (1999) Early post-settlement mortality in a coral reef fish and its effect on local population size. Ecol Monogr 69:177-194

Cowen RK, Castro LR (1994) Relation of coral-reef fish larval distributions to island scale circulation around Barbados, West Indies. Bull Mar Sci 54:228-244

Dalzell P (1996) Catch rates, selectivity and yields of reef fishing. In: Polunin NVC, Roberts CM (eds) Reef fisheries. Chapman \& Hall, London, p 161-192

Danilowicz BS, Tolimieri N, Sale PF (2001) Meso-scale habitat features affect recruitment of reef fishes in St. Croix, US Virgin Islands. Bull Mar Sci 69:1223-1232

Doherty PJ (1991) Spatial and temporal patterns in recruitment. In: Sale PF (ed) The ecology of fishes on coral reefs. Academic Press, San Diego, CA, p 261-293

Doherty PJ (2002) Variable replenishment and the dynamics of reef fish populations. In: Sale PF (ed) Coral reef fishes: dynamics and diversity in a complex ecosystem. Academic Press, San Diego, CA, p 327-359

> Doherty PJ, Fowler T (1994) An empirical test of recruitment limitation in a coral reef fish. Science 263:935-939

> Doherty PJ, Kingsford MJ, Booth DJ, Carleton J (1996) Habitat selection before settlement by Pomacentrus coelestis. Mar Freshw Res 47:391-399

Ebeling AW, Hixon MA (1991) Tropical and temperate reef fishes: comparison of community structures. In: Sale PF (ed) The ecology of fishes on coral reefs. Academic Press, San Diego, CA, p 509-563

> Fisher R (2005) Swimming speeds of larval coral reef fishes: impacts on self-recruitment and dispersal. Mar Ecol Prog Ser 285:223-232

Fisher R, Leis JM, Clark DL, Wilson SK (2005) Critical swimming speeds of late-stage coral reef fish larvae: variation within species, among species and between locations. Mar Biol 147:1201-1212

Forrester GE, Steele MA (2004) Predators, prey refuges, and the spatial scaling of density-dependent prey mortality. Ecology 85:1332-1342

Fortin MJ, Dale M (2005) Spatial analysis: a guide for ecologists. Cambridge University Press, Cambridge

Fowler AJ, Doherty PJ, Williams DM (1992) Multi-scale analysis of recruitment of a coral-reef fish on the Great Barrier Reef. Mar Ecol Prog Ser 82:131-141

Greig-Smith P (1983) Quantitative plant ecology, 3rd edn. Blackwell Scientific, Oxford

> Gutiérrez L (1998) Habitat selection by recruits establishes local patterns of adult distribution in 2 species of damselfishes: Stegastes dorsopunicans and S. planifrons. Oecologia 115:268-277

Hamilton SL, White JW, Caselle JE, Swearer SE, Warner RR (2006) Consistent long-term spatial gradients in replenishment for an island population of a coral reef fish. Mar Ecol Prog Ser 306:247-256

Hixon MA, Webster MS (2002) Density dependence in reef fish populations. In: Sale PF (ed) Coral reef fishes: dynamics and diversity in a complex ecosystem. Academic Press, San Diego, CA, p 303-326 
Hochberg Y (1988) A sharper Bonferroni procedure for multiple tests of significance. Biometrika 75:800-802

Holbrook SJ, Forrester GE, Schmitt RJ (2000) Spatial patterns in abundance of a damselfish reflect availability of suitable habitat. Oecologia 122:109-120

Holm S (1979) A simple sequentially rejective multiple test procedure. Scand J Stat 6:65-70

Hunt von Herbing I, Hunte W (1991) Spawning and recruitment of the bluehead wrasse Thalassoma bifasciatum in Barbados, West-Indies. Mar Ecol Prog Ser 72:49-58

Job SD, Bellwood DR (2000) Light sensitivity in larval fishes: implications for vertical zonation in the pelagic zone. Limnol Oceanogr 45:362-371

Jones GP (1991) Postrecruitment processes in the ecology of coral reef fish populations: a multi-factorial perspective. In: Sale PF (ed) The ecology of fishes on coral reefs. Academic Press, San Diego, CA, p 294-328

Kingsford MJ, Choat JH (1986) Influence of surface slicks on the distribution and onshore movements of small fish. Mar Biol 91:161-171

Kingsford MJ, Leis JM, Shanks A, Lindeman KC, Morgan SG, Pineda J (2002) Sensory environments, larval abilities and local self-recruitment. Bull Mar Sci 70:309-340

Lecchini D, Planes S, Galzin R (2005) Experimental assessment of sensory modalities of coral-reef fish larvae in the recognition of their settlement habitat. Behav Ecol Sociobiol 58:18-26

Legendre P, Legendre L (1998) Numerical Ecology, 2nd edn. Elsevier, Amsterdam

Leis JM (2006) Are larvae of demersal fishes plankton or nekton? Adv Mar Biol 51:57-141

Leis JM, McCormick MI (2002) The biology, behavior and ecology of the pelagic, larval stage of coral reef fishes. In: Sale $\mathrm{PF}$ (ed) Coral reef fishes: dynamics and diversity in a complex ecosystem. Academic Press, San Diego, CA, p 171-199

Lewis JB (1960) The coral reefs and coral communities of Barbados, W.I. Can J Zool 38:1133-1145

Luckhurst BE, Luckhurst K (1977) Recruitment patterns of coral reef fishes on the fringing reefs of Curaçao, Netherlands Antilles. Can J Zool 55:681-689

Luckhurst BE, Luckhurst K (1978) Analysis of the influence of substrate variables on coral reef fish communities. Mar Biol 49:317-323

Masterson CF, Danilowicz BS, Sale PF (1997) Yearly and inter-island variation in the recruitment dynamics of the bluehead wrasse (Thalassoma bifasciatum, Bloch). J Exp Mar Biol Ecol 214:149-166

McFarland WN, Brothers EB, Ogden JC, Shulman MJ, Bermingham EL, Kotchian-Prentiss NM (1985) Recruitment patterns in young French grunts, Haemulon flavolineatum (Family Haemulidae), at St. Croix, Virgin Islands. Fish Bull (Wash DC) 83:413-426

Milicich MJ, Doherty PJ (1994) Larval supply of coral-reef fish populations-magnitude and synchrony of replenishment to Lizard Island, Great-Barrier-Reef. Mar Ecol Prog Ser 110:121-134

Miller J, Beets J, Rogers C (2001) Temporal patterns of fish recruitment on a fringing coral reef in Virgin Islands National Park, St John, U.S. Virigin Islands. Bull Mar Sci 69:567-577

Moksnes PO, Heck KL (2006) Relative importance of habitat selection and predation for the distribution of blue crab megalopae and young juveniles. Mar Ecol Prog Ser 308:165-181

Mumby PJ, Dahlgren CP, Harborne AR, Kappel CV and others (2006) Fishing, trophic cascades, and the process of grazing on coral reefs. Science 311:98-101
Munday PL (2002) Does habitat availability determine geographical-scale abundance of coral-dwelling fishes? Coral Reefs 21:105-116

Öhman MC, Munday PL, Jones GP, Caley MJ (1998) Settlement strategies and distribution patterns of coral-reef fishes. J Exp Mar Biol Ecol 225:219-238

Oksanen J, Kindt R, Legendre P, O'Hara B (2005) vegan: community ecology package. Version 1.7-82. Available at: http://cc.oulu. fi/ jarioksa/

Paris CB, Cowen RK (2004) Direct evidence of a biophysical retention mechanism for coral reef fish larvae. Limnol Oceanogr 49:1964-1979

> Paula J, Silva IC, Francisco SM, Flores AV (2006) The use of artificial benthic collectors for assessment of spatial patterns of settlement of megalopae of Carcinus maenas (L.) (Brachyura: Portunidae) in the lower Mira Estuary, Portugal. Hydrobiologia 557:69-77

Pitcher CR (1988) Spatial variation in the temporal pattern of recruitment of a coral reef damselfish. Proc 6th Int Coral Reef Symp 2:811-816

Potts GW, McGuigan KM (1986) Preliminary survey of the distribution of postlarval fish associated with inshore reefs and with special reference to Gobiusculus flavescens (Fabricius). Prog Underwat Sci 11:15-25

Pyper BJ, Peterman RM (1998) Comparison of methods to account for autocorrelation in correlation analyses of fish data. Can J Fish Aquat Sci 55:2127-2140

Rilov G, Figueira WF, Lyman SJ, Crowder LB (2007) Complex habitats may not always benefit prey: linking visual field with reef fish behavior and distribution. Mar Ecol Prog Ser 329:225-238

Robertson DR (1990) Differences in the seasonalities of spawning and recruitment of some small neotropical reef fishes. J Exp Mar Biol Ecol 144:49-62

Robertson DR, Kaufmann KC (1998) Assessing early recruitment dynamics and its demographic consequences among tropical reef fishes: accommodating variation in recruitment seasonality and longevity. Aust J Ecol 23:226-233

> Robertson DR, Green GD, Victor CB (1988) Temporal coupling of production and recruitment of larvae of a Caribbean reef fish. Ecology 69:370-381

Sale PF (1998) Appropriate spatial scales for studies of reeffish ecology. Aust J Ecol 23:202-208

Sano M (1997) Temporal variation in density dependence: recruitment and postrecruitment demography of a temperate zone sand goby. J Exp Mar Biol Ecol 214:67-84

Schmitt RJ, Holbrook SJ (1999) Settlement and recruitment of three damselfish species: larval delivery and competition for shelter space. Oecologia 118:76-86

Shima JS (1999) Variability in relative importance of determinants of reef fish recruitment. Ecol Lett 2:304-310

Shima JS (2001) Recruitment of a coral reef fish: roles of settlement, habitat, and postsettlement losses. Ecology 82: 2190-2199

> Sponaugle S, Cowen RK (1996a) Larval supply and patterns of recruitment for two Caribbean reef fishes, Stegastes partitus and Acanthurus bahianus. Mar Freshw Res 47: 433-447

Sponaugle S, Cowen RK (1996b) Nearshore patterns of coral reef fish larval supply to Barbados, West Indies. Mar Ecol Prog Ser 133:13-28

Sponaugle S, Cowen RK (1997) Early life history traits and recruitment patterns of Caribbean wrasses (Labridae). Ecol Monogr 67:177-202

Sponaugle S, Pinkard DR (2004) Impact of variable pelagic environments on natural larval growth and recruitment of the reef fish Thalassoma bifasciatum. J Fish Biol 64:34-54 
Steele MA (1997) Population regulation by post-settlement mortality in two temperate reef fishes. Oecologia 112:64-74

Steele MA, Forrester GE (2002) Early postsettlement predation on three reef fishes: effects on spatial patterns of recruitment. Ecology 83:1076-1091

Stevens BG, Kittaka J (1998) Postlarval settling behavior, substrate preference, and time to metamorphosis for red king crab Paralithodes camtschaticus. Mar Ecol Prog Ser 167: 197-206

Stobutzki IC, Bellwood DR (1997) Sustained swimming abilities of the late pelagic stages of coral reef fishes. Mar Ecol Prog Ser 149:35-41

ter Braak CJF, Smilauer P (2002) Canoco reference manual and CanoDraw for Windows user's guide: software for canonical community ordination (Version 4.5). Microcomputer Power, Ithaca, NY

Thompson KR, Page FH (1989) Detecting synchrony of recruitment using short, auto-correlated time-series. Can J Fish Aquat Sci 46:1831-1838

Thorrold SR, Shenker JM, Wishinski E, Mojica R, Maddox ED (1994) Larval supply of shorefishes to nursery habitats around Lee-Stocking Island, Bahamas. I. Small-scale distribution patterns. Mar Biol 118:555-566

Tolimieri N (1995) Effects of microhabitat characteristics on the settlement and recruitment of a coral-reef fish at two spatial scales. Oecologia 102:52-63

Tolimieri N (1998a) The relationship among microhabitat characteristics, recruitment and adult abundance in the stoplight parrotfish, Sparisoma viride, at three spatial scales. Bull Mar Sci 62:253-268

Tolimieri N (1998b) Effects of substrata, resident conspecifics and damselfish on the settlement and recruitment of the stoplight parrotfish, Sparisoma viride. Environ Biol Fishes 53:393-404

Editorial responsibility: Jon Hare, Narragansett, Rhode Island, USA
Tolimieri N, Sale PF, Nemeth RS, Gestring KB (1998) Replenishment of populations of Caribbean reef fishes: Are spatial patterns of recruitment consistent through time? J Exp Mar Biol Ecol 230:55-71

Tupper M, Hunte W (1994) Recruitment dynamics of coralreef fishes in Barbados. Mar Ecol Prog Ser 108:225-235

Vallès H (2008) Spatial and temporal patterns of recruitment of coral reef fishes to the west coast of Barbados (West Indies): an approach using a novel standard unit of settlement habitat. PhD thesis, McGill University, Montreal

Vallès H, Kramer DL, Hunte W (2006) A standard unit for monitoring recruitment of fishes to coral rubble. J Exp Mar Biol Ecol 336:171-183

Victor BC (1983) Settlement and larval metamorphosis produce distinct marks on the otoliths of the slippery dick, Halichoeres bivittatus. In: Reaka ML (ed) The ecology of deep and shallow coral reefs. Underwat Res Symp Ser, Vol 1. NOAA, Rockville, MD, p 47-51

Victor BC (1984) Coral-reef fish larvae - patch size estimation and mixing in the plankton. Limnol Oceanogr 29: 1116-1119

> Victor BC (1986) Larval settlement and juvenile mortality in a recruitment-limited coral-reef fish population. Ecol Monogr 56:145-160

Walsh WJ (1987) Patterns of recruitment and spawning in Hawaiian reef fishes. Environ Biol Fishes 18:257-276

Warner RR, Hughes TP (1988) The population dynamics of reef fishes. Proc 6th Int Coral Reef Symp 1:149-155

- Wellington GM (1992) Habitat selection and juvenile persistence control the distribution of two closely related Caribbean damselfishes. Oecologia 90:500-508

Zar JH (1999) Biostatistical analysis, 4th edn. Prentice Hall, Upper Saddle River, NJ

Submitted: December 19, 2006; Accepted: January 29, 2008

Proofs received from author(s): June 24, 2008 